\title{
The potential of involving traditional practitioners in the scaling up of male circumcision in the context of HIV prevention in Tanzania
}

\author{
STELLA P. KILIMA*, ELIZABETH H. SHAYO, JUDITH MSOVELA, KESHENI P. SENKORO, \\ BENJAMIN K. MAYALA, LEONARD E.G. MBOERA and JULIUS J. MASSAGA \\ National Institute for Medical Research, P.O. Box 9653, Dar es Salaam, Tanzania
}

\begin{abstract}
Male circumcision (MC) has been practiced worldwide for religious, cultural, social and medical reasons. Recent studies in Africa have indicated that MC to be highly protective against HIV transmission. However, incorporating MC in HIV/AIDS prevention programme will increase its demand in Tanzania where traditional male circumcision is common and the health care system is weak. The objective of this study was to determine the challenges and opportunities of involving traditional practitioners in scaling up safe MC in the context of HIV prevention in Tanzania. The study was conducted in Monduli, Bahi and Mkuranga districts of Tanzania. Both quantitative and qualitative methods were employed. Household survey involved community members from the selected villages. Indepth interviews involved traditional practitioners and key informants at national, district and facility levels. A total of 601 householders were interviewed. Most (71.4\%) household respondents preferred traditional MC as it was part of their culture and tradition. A similar response was obtained from other respondents. It was mostly preferred because it was used as an initiation school, turning of boys to warriors and sense of social cohesion. Only 228 (37.9\%) of the respondents were aware of the adverse events associated with MC. The most frequently mentioned adverse effects were severe bleeding $(65.0 \%)$, delayed wound healing (17.5\%) and wound sepsis (8.4\%). The risk of acquiring HIV through male circumcision practice was poorly known among community members except medical respondents. Single unsterilized local surgical equipment was used to circumcise several initiates. It was observed that interference with traditional values associated with circumcision to be the main hindrance of linkage between traditional and conventional practitioners. On the other hand it was reported that there was no policy or guidelines on Traditional MC (TMC). Most of respondents supported the efforts to establish and promote formal linkages between traditional and conventional practitioners. In conclusion, under the current HIV pandemic and TMC being prevalent in Tanzania, it is high time for the government to establish a linkage between traditional and conventional practitioners for safe practices in order to minimize HIV transmission.
\end{abstract}

Keywords: male, circumcision, traditional, clinical, practitioners, HIV/AIDS, Tanzania

\section{Introduction}

Male circumcision is the surgical removal of all or part of the foreskin of the penis. It is the oldest known surgical procedure and widely practiced around the world, mostly for religious or social custom reasons. It is estimated that globally and Africa, about $30-40 \%$ and $68 \%$ of men are circumcised, respectively. Global estimates in 2006 suggest that about $30 \%$ of males, representing a total of approximately 670 million men, were circumcised. In Africa, $68 \%$ of the men are estimated to be circumcised (www.avac.org/; Hankin, 2006).

\footnotetext{
* Correspondence: Stella P. Kilima; E-mail: stellakilima@yahoo.com
} 
Male circumcision is common in many African countries, and is almost universal in North Africa and most of West Africa (WHO/UNAIDS, 2007). The prevalence of male circumcision in East Africa varies from country to country. It is low (15\%) in Burundi and Rwanda and it is high (70-84\%) in Tanzania and Kenya (WHO/UNAIDS, 2007). In most African societies where males are circumcised between the ages of 6 and 15 years, the main reason is ritual practice (Nnko et al., 2001; Bailey \& Egesah, 2006). Circumcision is thought to enhance penile hygiene, reduce incidence of sexually transmitted infections (STIs) among men, and shorten the duration or lessen the infectiousness of STIs. In some communities, male circumcision is believed to enhance sexual pleasure (Myers et al., 1985).

Traditional male circumcision among Tanzanians varies across different tribes and culture. It is common among pastoralists and tribes along the eastern coast (mostly Moslems). However, like in the other East African countries, the Bantu-speaking groups do not traditionally practice male circumcision (Bailey \& Egesah, 2006). Similarly, male circumcision is not a tradition among communities of the Lake Victoria Basin in Tanzania, comprising of large tribes of the Sukuma, Haya and Nyamwezi. Yet, it is a common tradition among smaller tribes of the Jita, Kwaya, Zanaki, Ikizu, and Kurya (Dogde \& Kaviti, 1965). The growth of urban centres and the establishment of district capitals with public servants from all over the country has led to increased mixing of circumcising and non-circumcising ethnic groups- making male circumcision been adopted and popular among traditionally non-circumcising tribes (Urassa et al., 2001).

There has been an increasing interest in the practice of male circumcision in Africa because of its association with HIV infection. Studies have shown that sub-Saharan countries with the highest HIV prevalence are those in which male circumcision is little practiced (Halperin \& Bailey, 1999; Moses et al., 1990; Westercamp \& Bailey, 2007). Recently, three randomized efficacy trials conducted in Orange Farm in South Africa (Auvert et al., 2005), Kisumu in Kenya (Bailey et al., 2007) and Rakai in Uganda (Gray et al., 2007) have shown that circumcised men were less than half likely to become infected with HIV than those who were uncircumcised. A mathematical modelling, based on the South African trial, estimates that the male circumcision could avert two million new HIV infections and 300,000 HIV-related deaths over the next 10 years in sub-Saharan Africa (Williams et al., 2006). Moreover, male circumcision may be a cost-effective tool not only in the fight against HIV but also against other sexual and reproductive health problems (Mills et al., 2008).

Based on the evidence from various studies, in early 2007, the UNAIDS and WHO announced recommendations to scale-up male circumcision as an additional intervention to reduce the risk of heterosexually acquired HIV infection in men (http://www.who.int/hiv/mediacentre/). With latest research findings suggesting that circumcised men have a significantly lower risk of becoming infected with HIV (Patterson et al., 2002; Donoval et al., 2006); demand for safe, affordable, male circumcision is expected to increase rapidly. The fact that the health care system in Tanzania is facing acute shortage of skilled health workers and working tools suggests that traditional male circumcision could be viewed as the best alternative but complementary way for scaling up safe circumcision. However, there is limited evidence-based information on how traditional male circumcision could be made feasible in providing safe and affordable services in Tanzania. This study was 
therefore carried out to determine the challenges and opportunities for the involvement of traditional practitioners in scaling up safe male circumcision in the context of HIV prevention in Tanzania.

\section{Materials and Methods}

\section{Study area, design and sample size}

This descriptive cross-sectional study was conducted in Monduli, Mkuranga and Bahi districts of northern, eastern and central Tanzania, respectively. The selection of districts specifically targeted the Maasai (Monduli), Gogo (Bahi) and Zaramo (Mkuranga) who are known to practice traditional circumcision. The study employed both qualitative and quantitative techniques in data collection. The sample size for the quantitative data was determined using WHO Sample Size Determination in Health Studies (Lwagwa \& Lemeshow 1990-2000) basing on $95 \%$ confidence interval (CI), anticipated population proportion (50\%), precision (relative and absolute) and population size. Probability Proportional to Size was used to determine the proportional sample of study participants to be interviewed from each of the three districts. To select the household two wards were selected from each district. Thereafter, one village was picked from each ward where TMC was most practiced. Simple random sampling technique was used to select the households. The head of the household (father or mother) were alternatively interviewed.

Qualitative data was collected through in depth interviews to different categories of informants from national to community level. At national level, informants from Medical Stores Department, Ministry of Health and Social Welfare; Association of Traditional Health Practitioners, Muhimbili National Hospital and Aga Khan Hospital were involved. At the district level interviewees included members of the Council Health Management Team, District Planning Officer, District Administrative Secretary, Community Development and District Cultural Officers. A number of personnel at health care facilities were involved. This included in-charges of the selected facilities, clinicians, laboratory personnel, anaesthetists, pharmacists and nurses. At community level traditional practitioners were interviewed.

At Ward level, 10 traditional practitioners were purposely selected and interviewed. They were identified by Ward leaders and by young men who had undergone circumcision. In each district, health facility workers (clinicians) from 1 hospital, 2 health centres and $10 \%$ of all dispensaries, were selected and interviewed, to assess their level of training, and experience with the MC procedure.

\section{Data collection}

Pre-tested Kiswahili questionnaire was used in the interviews. All participants were asked questions regarding their preference on circumcision mode, categories of traditional practitioners, their characteristics and practices as per cultural background, experience on traditional circumcision and any reported complications. Similarly, their views on partnership with traditional practitioners and health workers were sought. 


\section{Data analysis}

Quantitative data were double entered into a computer using EPIDATA software. Data analysis was structured using both STATA and SPSS. Descriptive analysis was used to obtain different types of proportional. Qualitative data were analysed manually using matrices. Identification of major themes according to specific objectives and establishment of possible relationships was performed.

\section{Conceptual definition}

For the purposes of this study, circumcisions performed at a health facility (hospital, health centre, and dispensary) by anyone considered by the participants to be a trained clinician was categorized as "clinical circumcision". All others performed by non-medical personnel were categorized as "traditional circumcision".

\section{Ethical Considerations}

Permission to conduct a study was sought from regional and district authorities. Information on purpose and procedure for conducting the study (including the right to refuse or withdraw at any time, confidentiality and privacy) was explained to all interviewees. This study received ethical approval from the Medical Research Coordinating Committee of the National Institute for Medical Research (NIMR/HQ/R. 8a/Vol IX/783).

\section{Results}

\section{Household interviews}

A total of 601 individuals were interviewed. Of this, 54.1\% were males and $45.9 \%$ were females. The mean age $( \pm \mathrm{SD})$ of the respondents was $36 \pm 12,45 \pm 16$ and $38 \pm 15$ years in Bahi, Mkuranga and Monduli district, respectively. Married individuals accounted for the majority (85\%) of the respondents. About half (51.1\%) of the respondents had primary school education. Only 3\% had education above primary school. The illiteracy rate was highest (55.5\%) in Monduli. Most $(74.0 \%)$ of the respondents were peasants (Table 1$)$.

Of the 601 respondents, 88.2\% (Bahi=75.1\%; Mkuranga $=99.3 \%$; Monduli $=97.0 \%$ ) admitted that circumcision is a common practice among their communities, of which Traditional male circumcision (TMC) was the most preferred than CMC (Table 2). Overall, 83\% of the respondents said TMC was accepted in their community. The majority were from Monduli (98.0\%) followed by Mkuranga (93.8\%) and Bahi (66.2\%). Some of the respondents preferred any of the two (clinical or traditional) depending on the accessibility as they were not restricted by their culture. Circumcision was either done in groups or individual initiates. Group traditional male circumcision ceremony was common (46.9\%) among the communities in the three districts. It was most prevalent (59\%) among communities in Monduli than in Bahi (49.8\%) and Mkuranga (25.0\%). 
Table 1: Demographic characteristics of the household respondents

\begin{tabular}{|c|c|c|c|c|}
\hline Variable & Bahi $(\mathrm{N}=257)$ & Mkuranga (N=144) & Monduli (N=200) & Total $(=601)$ \\
\hline \multicolumn{5}{|l|}{ Sex } \\
\hline Male & $153(59.5)$ & $67(46.5)$ & $105(52.5)$ & $325(54.1)$ \\
\hline Female & $104(40.5)$ & $77(53.5)$ & $95(47.5)$ & $276(45.9)$ \\
\hline Mean age (SD) & $36(12)$ & $45(16)$ & $38(15)$ & $39(14)$ \\
\hline \multicolumn{5}{|l|}{ Education status } \\
\hline Primary education & 157(61.1) & $69(47.9)$ & $81(40.5)$ & $307(51.1)$ \\
\hline No formal education & $94(36.6)$ & $69(47.9)$ & $111(55.5)$ & $274(45.6)$ \\
\hline Secondary education & $5(2.0)$ & $4(2.8)$ & $7(3.5)$ & $16(2.7)$ \\
\hline Higher education & $1(0.4)$ & $2(1.4)$ & $1(0.5)$ & $4(0.7)$ \\
\hline \multicolumn{5}{|l|}{ Occupation } \\
\hline Crop farming & $236(91.8)$ & $111(77.1)$ & $98(49.0)$ & $445(74.0)$ \\
\hline Cattle keeping & $5(2.0)$ & $0(0.0)$ & $89(44.5)$ & $94(15.6)$ \\
\hline Petty Business & $3(1.2)$ & $18(12.5)$ & $4(2.0)$ & $25(4.2)$ \\
\hline Public service & $3(1.2)$ & $6(4.2)$ & $2(1.0)$ & $11(1.8)$ \\
\hline Self employment & $6(2.3)$ & $2(1.4)$ & $2(1.0)$ & $10(1.7)$ \\
\hline Home wife & $2(0.8)$ & $4(2.8)$ & $4(2.0)$ & $10(1.7)$ \\
\hline Others & $2(0.8)$ & $3(2.1)$ & $1(0.5)$ & $6(1.0)$ \\
\hline \multicolumn{5}{|l|}{ Marital status } \\
\hline Married & $213(82.9)$ & $123(85.4)$ & $175(87.5)$ & $511(85.0)$ \\
\hline Widow & $13(5.1)$ & $10(6.9)$ & $7(3.5)$ & $30(5.0)$ \\
\hline Single & $26(10.1)$ & $8(5.6)$ & $18(9.0)$ & $52(8.7)$ \\
\hline Separated & $3(1.2)$ & $1(0.7)$ & $0(0.0)$ & $4(0.7)$ \\
\hline Divorced & $2(0.8)$ & $2(1.4)$ & $0(0.0)$ & $4(0.7)$ \\
\hline
\end{tabular}

A total of $340(56.6 \%)$ respondents were aware of the availability of traditional practitioners in their communities which was $92.4 \%, 55.3 \%$ and $32.5 \%$ of the respondents in Mkuranga, Bahi and Monduli, respectively. In Bahi and Mkuranga, traditional practitioners were indigenous people who were living within the community members. In Monduli, they were living in isolation (away from the rest of the communities) and were only invited when needed.

Table 2: Proportion of respondents on preference of types of male circumcision practices

\begin{tabular}{lllll}
\hline Type of circumcision & Bahi (257) & Mkuranga (144) & Monduli (200) & Overall (601) \\
\hline Traditional & $124(48.3)$ & $112(77.8)$ & $193(96.5)$ & $429(71.4)$ \\
Clinical & $111(43.2)$ & $12(8.3)$ & $3(1.5)$ & $126(21.0)$ \\
$\begin{array}{l}\text { Any of the two ( Traditional } \\
\text { or Clinical) }\end{array}$ & $21(8.2)$ & $18(12.5)$ & $0(0.0)$ & $39(6.5)$ \\
Don't know & $1(0.4)$ & $2(1.4)$ & $4(2.0)$ & $7(1.2)$ \\
\hline
\end{tabular}


The majority of the respondents (83.7\%) were of the opinion that TMC practices were similar among the practitioners within their respective areas. Only 16.3\% (Bahi $=16 \%$; Mkuranga=14.6; Monduli $=18 \%$ ) said that there were some differences in practice. Both Maasai and Gogo leave a small piece of fore skin which is used as an identification and Zaramo remove all fore skin as they believe it is a hygienic and against their religious beliefs, these differences were attributed by their cultural differences.

Table 3: Reasons for preference of traditional male circumcision

\begin{tabular}{lllll}
\hline Reasons & $\begin{array}{l}\text { Bahi } \\
(\mathbf{n}=\mathbf{1 3 7 )}\end{array}$ & $\begin{array}{l}\text { Mkurang } \\
\mathbf{a}(\mathbf{n}=\mathbf{9 6})\end{array}$ & $\begin{array}{l}\text { Monduli } \\
(\mathbf{n}=\mathbf{1 6 7 )}\end{array}$ & $\begin{array}{l}\text { Overall } \\
(\mathbf{n}=\mathbf{4 0 0})\end{array}$ \\
\hline Initiation school & $80(58.4)$ & $37(38.5)$ & $119(71.3)$ & $236(59.0)$ \\
Changing of boy to manhood (warrior) & $0(0.0)$ & $0(0.0)$ & $110(65.9)$ & $110(27.5)$ \\
Sense of social cohesion & $19(13.9)$ & $8(8.3)$ & $59(35.3)$ & $86(21.5)$ \\
As a gift from his family, relatives and friends & $30(21.9)$ & $26(27.1)$ & $60(35.9)$ & $116(29.0)$ \\
Other & $16(11.7)$ & $31(32.3)$ & $26(15.6)$ & $73(18.3)$ \\
\hline
\end{tabular}

In Monduli, male circumcision was done when boys were at the age of 8-25 years because they were believed to be matured enough to take care of livestock and other properties. In Bahi circumcision was done to the younger groups of about 7 years. However, this depended on the parent's decisions and availability of food. There was no specific age for male circumcision in Mkuranga. Circumcisions among the Maasai were performed after every seven years, whereby boys were being circumcised and attend the initiation process in a group.

Table 4: Disadvantage of traditional male circumcision

\begin{tabular}{|c|c|c|c|c|}
\hline Reasons & $\begin{array}{l}\text { Bahi } \\
(n=126)\end{array}$ & $\begin{array}{l}\text { Mkuranga } \\
(\mathrm{n}=57)\end{array}$ & $\begin{array}{l}\text { Monduli } \\
(\mathrm{n}=71)\end{array}$ & $\begin{array}{l}\text { Overall } \\
(\mathrm{n}=254)\end{array}$ \\
\hline Pains & $75(59.5)$ & $32(56.1)$ & $54(76.1)$ & $161(63.4)$ \\
\hline Higher costs & $56(44.4)$ & $24(42.1)$ & $47(66.2)$ & $127(50.0)$ \\
\hline Burden of hosting people for elaborate ceremony & $1(0.8)$ & $0(0.0)$ & $61(85.9)$ & $62(24.4)$ \\
\hline Fatigue due to long period of ceremonies & 20(15.9) & $6(10.5)$ & 14(19.7) & $40(15.8)$ \\
\hline $\begin{array}{l}\text { High risk of HIV infection through sharing of the } \\
\text { knife }\end{array}$ & $9(7.1)$ & $21(36.8)$ & $7(9.9)$ & $37(14.6)$ \\
\hline Disruption from school attendance & $7(5.6)$ & $3(5.3)$ & $2(2.8)$ & $12(4.7)$ \\
\hline Traditional rites are against Christian teachings & $4(3.2)$ & $0(0.0)$ & $3(4.2)$ & $7(2.8)$ \\
\hline Others & $10(7.9)$ & $5(8.8)$ & $1(1.4)$ & $16(6.3)$ \\
\hline
\end{tabular}

Two thirds $(66.6 \%)$ of the respondents could mention at least one reason for the preference of traditional male circumcision. Generally, 59\% (236) of the respondents preferred traditional male circumcision because the ceremony was used as an initiation school for boys. This was mentioned more frequently in Monduli than in Bahi and Mkuranga (Table 3).It was in such avenues that boys are taught to be self-dependents and how to care for the family and livestock. About one-third (Monduli=35.9\%; Mkuranga=27.1\%; Bahi=21.9\%) of the respondents 
considered traditional circumcision as a gift to the boy from the family, friends and relatives. Other reasons for preference of traditional circumcision included making the boy a courageous and as a sense of social cohesion with peers. Circumcision was considered as a process of turning boys into warriors among $65.9 \%$ of the respondents in Monduli.

District-wise, $49 \%, 39.6 \%$ and 35.5\% of the respondents in Bahi, Mkuranga and Monduli, respectively, knew at least one disadvantage of traditional male circumcision. The frequently mentioned disadvantages of TMC were too much pain to the boys (63.4\%) and high costs (50\%). Surprisingly high risk of HIV transmission was only mentioned by a small proportion (14.6\%) of the respondents (Table 4). Sixteen (2.7\%) and 141 (23.5\%) respondents knew individuals who experienced adverse events due to either clinical or traditional circumcision respectively (Figure 1). Most of the adverse events were reported from Bahi district. Severe bleeding was the most adverse event mentioned by the respondents (65.0\%). Other significant adverse events included delayed wound healing (17.5\%) and wound sepsis (8.4\%). Amputation of penis or deaths was mentioned by only 3 respondents.

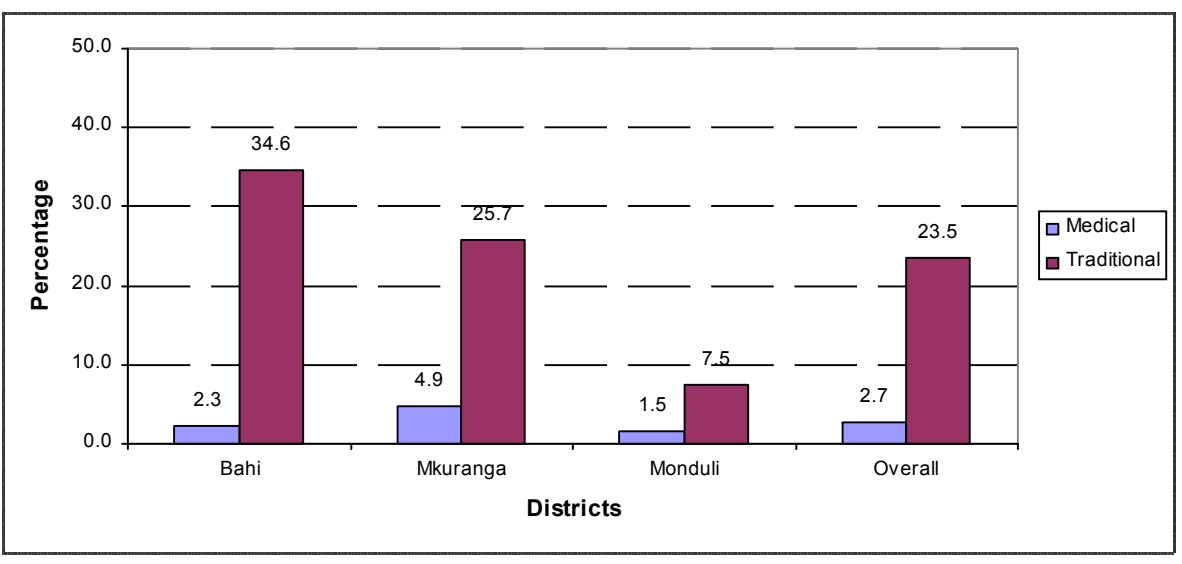

Figure 1: Proportion of respondents aware of adverse events due to either medical or traditional MC

When the respondents were asked that given a choice, what type of circumcision they would prefer for their sons to undergo, only about half (52.8\%) mentioned clinical circumcision; the majority were from Bahi (77.8\%). Traditional circumcision was the choice for majority (76\%) of the respondents from Monduli. In $45.9 \%$ of the respondents, the decision for male circumcision was made by the father. Whereas the father was mentioned by the majority in Monduli, both the father and mother were involved in making decision in Mkuranga. A total of 304 (50.6\%) respondents said that informed consent was usually sought from boys before circumcision. The proportion was relatively higher in Monduli (80.5\%) than in Bahi (47.5\%) and Mkuranga $(14.6 \%)$.

Only 20.6\% (124/601) of the respondents were aware of any kind of cooperation between traditional and conventional (clinical) circumcisers. The responses were higher in Bahi (24.5\%), followed by Monduli (18.5\%) and Mkuranga (16.7\%). The cooperation between the two groups was described to involve meetings, trainings of traditional practitioners by health workers; visits of health workers to traditional practitioners and transfer of complicated cases from 
traditional practitioners to conventional health facilities. A total of $405(67.4 \%)$ of the respondents were of the view that it is important to establish and promote linkages between traditional and conventional health providers. Most of them were from Mkuranga (75.7\%), followed by Monduli (68.5\%) and Bahi (61.9\%).

\section{In-depth interviews}

Traditional Practitioners: A total of 24 traditional practitioners (23-85 years old) were involved in the survey. These included 13 from Mkuranga, 7 from Bahi and 4 from Monduli. Over half of the practitioners (14/24) had no formal education and farming was their main (20/24) income generating activity. Overall, traditional practitioners claimed to have adequate skills in performing circumcision through long years of experience. Most of them had been engaged in this activity for more than three years and they have been circumcising between 20 and 200 clients per year. There was a general agreement from all traditional practitioners that members of their communities preferred traditional than clinical male circumcision due to cultural reasons. Most of the traditional practitioners learned the practice from their fathers or grandfathers. Few of them admitted to have learnt by seeing other people performing circumcision, as confirmed by the following expression "I learned from my father, he taught me how to circumcise and how to use both traditional and modern medicine" (Traditional Practitioner, Mkuranga).

Most of the Traditional practitioners were using razor or knives for circumcision and cotton wool for dressing wounds. A few practitioners used the same knife to circumcise more than one person, "I do use a single knife to circumcise three initiates at a time. After that I clean it with cotton wool before using it to second group" (Traditional Practitioner, Mkuranga).

Traditional practitioners said that circumcision was done either in groups or individual. "We circumcise once per year in groups and one group might have 40-50 youth" (Traditional Practitioner, Bahi). The costs for the circumcision differed from one practitioner to another even within the same district. Most of the traditional practitioners were charging between TShs 5,000 and 10,000 per person. Material things and in-kind payments were also accepted. Payments were done after circumcision procedure has been completed.

All traditional practitioners admitted to have no formal relationship with conventional practitioners, though sometimes they would consult health personnel when they have complicated cases or requesting for drugs. Strategies on how to strengthen linkage between traditional and conventional practitioners were mentioned to include provision of education on HIV prevention; safe circumcision; use of injectable drugs; care of wounds; and use modern equipment. They emphasized the need to establish forums for information exchange between the groups.

Facility level key informants: A total of 38 healthcare providers from 10 dispensaries, six health centres and two district hospitals participated in the study. Thirty-one $(81.6 \%)$ health workers were aware that their respective communities prefer mostly traditional than conventional male circumcision. The main reasons for TMC preferences were low cost, culture and tradition, increase in sexual power and pleasure. Moreover, traditional circumcision

observes the community cultural values and is part of their rituals where boys receive 
adulthood training. The practice which is done without anaesthetics makes the boys braver. Anaesthesia during circumcision was perceived to reduce sexual desire.

Most of health workers had a positive outlook of traditional male circumcision although some described it as unsafe and unhygienic. It was noted that, circumcisions were done in poor hygienic environment and using unsterilized knives, hence contributing to poor wound healing and other post-circumcision complications. It was pointed out that, traditional practitioners were not much aware of modes of HIV/AIDS transmission hence they used the same "ritual" knife to more than one clients without sterilization.

About one third (12/38) of health workers mentioned that there was some kind of informal collaboration between traditional and conventional practitioners. Often the cooperation was on friendly basis. Twelve health personnel from Bahi and 8 from Mkuranga mentioned that some kind of collaboration existed especially in the management of complications associated with circumcision. Such co-operation was not mentioned by health workers in Monduli. Lack of formal collaboration between health workers and traditional practitioners was due to the fact that the later fear the former would interfere with traditional values associated with circumcision.

A number of areas of collaboration were proposed. These included the need for traditional practitioners to refer complicated cases to conventional health care facilities; training to traditional practitioners on safety and hygienic circumcision procedures; provision of surgical kits to traditional practitioners; and training of traditional practitioners on record keeping. It was also felt by the health workers that traditional practitioners should be urged to take their clients to health facilities for circumcision and thereafter continue with traditional rituals. Health workers admitted that they had something to learn from TMC practitioners. Given opportunity, they would like to learn from traditional practitioners on how to control bleeding; manage complications; and preparation and use of herbal anaesthetics.

All 38 interviewees were in favour of the move to promote a partnership between conventional and traditional practitioners. They expect that the linkage would fill the existing gaps between the two practitioners; would minimize chances of HIV transmission and would improve management of wound and complications. As a prerequisite to this partnership, health workers suggested, for the government and other partners to sensitize traditional practitioners and the community at large, of the advantages of safe and hygienic circumcision while observing respective culture and customs. A number of suggestions were made by health workers in order to accommodate traditional practitioners. Educating traditional practitioners on the need for safe and hygienic procedures so as to minimise transmission of infections including HIV/AIDS was of paramount importance. They proposed that, health personnel should have the role and responsibility to supervise the safety and hygienic issues without interfering with the cultural procedures. The government should support traditional practitioners with required medical supplies (e.g. surgical kits) for circumcision. To improve hygiene and minimize transmission of HIV they suggested that the government should construct special premises for traditional male circumcisers and equip them with required supplies and traditional male circumcision should be done within health facility buildings under the supervision of health personnel. They proposed a fee of US\$ 0.85-9.3 (TShs. 1,000$15,000)$ to be charged per single circumcision. 
District level key informants: A total of 18 informants were interviewed in the three districts. All key informants admitted that traditional practitioners were available in their districts. They associated the high preference for traditional circumcision to culture and traditions. TMC was considered to be safe than clinical circumcision, and it increases sexual pleasure during love making. Moreover, in addition to the fact that clinical circumcision was considered to be expensive, it was a sign of bravery, endurance and a qualification of becoming a warrior. All informants reported that registration of traditional practitioners doesn't exist so it was not possible for them to know the correct numbers of traditional practitioners.

In the three districts, two types of practitioners were identified. These included those who practice traditional circumcision only; and those who practice both male circumcision and traditional healing. According to key informants, in all districts, traditional circumcision ceremonies were done in groups. All eligible boys were brought to an identified place ready for circumcision followed by a traditional ceremony. However, in Mkuranga some informants said that some few parents would only send their own sons for circumcision when they feel that they deserve to be circumcised. In Bahi district, male circumcision was usually done annually during the harvesting season while in Monduli it was during a specific season after every 7 years.

All informants in the three district said that majority of people prefer traditional circumcision as part of their customs and traditions. One had this to say: "people believe that traditional circumcision is safe because it makes youth to be recognized in the community and becomes a warrior. (District Key Informant, Mkuranga). Negative perception towards clinical circumcision made people to prefer traditional: "community members believe that if a boy is circumcised at a health facility, he will lose his sexual potency when he grows older" (District Key Informant, Monduli).

All district informants, except one, supported traditional male circumcision as part of the customs and traditions. They all insisted that the practice must be performed in hygienic environment. They were of the opinion that the practice should be done at a health facility to ensure safety, hygiene, control of bleeding and can reduce risk of HIV transmission. In Bahi, some efforts were made by the district authority to urge traditional practitioners to bring children to health facilities for male circumcision and later continue with their traditional procedures. In Mkuranga, some traditional practitioners would usually communicate with clinicians and request drugs to treat circumcision wounds. All the district informants insisted on the importance of having good relationship with traditional practitioners to facilitate registration and monitoring of their practices.

All key informants supported the desire to involve traditional practitioners in scaling up male circumcision in the context of HIV prevention. In addition, they recommended for the government to identify and register traditional practitioners. It was also proposed that a situation analysis be carried out to document how traditional circumcision practice is been carried out by different groups in the country. This will help to identify areas for improvement. Education should be provided to both conventional and traditional practitioners. A motivation to traditional practitioner (including free surgical circumcision kits) should be considered as it was for traditional birth attendants. In terms of payment, most said that traditional practitioners should receive wages/salaries, but the rates should depend on the present environment because 
most traditional practitioner usually receives materials things instead of cash. However the average rates of US\$ 3.1-12.4 (TShs. 5,000-20,000) was recommended for a cost of circumcision per person, depending on the economic level of the client.

A number of challenges towards scaling up of male circumcision were identified by the district key informants. These included: (i) Inadequate surgical equipment and medical supplies; (ii) Poor sterilization system (boiling using firewood as there is no electrical power); (iii) Shortage of human resources; (iv) and lack of theatre facilities. The fact that female workers were not accepted by the community to carry out male circumcision was also identified as a challenge. Other challenges include: conflicts between circumcision as medical intervention and marks of ethnic identity; current scarcity of formal economic justifications for circumcision relative to other HIV-prevention strategies; potential burdens of the intervention on already fragile health systems; and the impact of male circumcision promotion on the women's ability to negotiate condom use with circumcised partners.

National Level Key Informants: Responses from 16 key informants were interviewed. All informants admitted that traditional male circumcision is been practised in Tanzania. However they acknowledged that it is not covered under Traditional and Alternative Medicine Act of 2002; and that there were no policy guidelines on circumcision in the country. They were of the opinion that the government should establish a department or unit to provide guidance of the traditional male circumcision practices. Most of the respondents proposed to have traditional male circumcision operate under the Ministry of Health and Social Welfare.

Majority of the informants recommended that people should be made aware on importance of male circumcision in the prevention of HIV transmission. However few were of the opinion that male circumcision should not be compulsory regardless of its importance as a measure to minimize the risk of contracting HIV and other sexually transmitted infections. They viewed it as a personal issue and therefore making it compulsory would likely to violate human rights. It would also interfere with culture and norms in areas where circumcision in not traditionally done.

Most of the respondents pointed a number of challenges that hinder collaboration between traditional and conventional practitioners. These included the fact that (i) conventional practitioners and traditional practitioners are two different disciplines, each one with its own principles and procedures; (ii) traditional practitioners are not legally recognized; (iii) traditional practitioners are not transparent on how they carry out the procedure; (iv) there is no use of anaesthetics during traditional male circumcision; (v) there is no forum or platform which links between traditional and conventional practitioners; and (vi) there are no policy guidelines which direct the two parties on how to work together. Some respondents pointed out that, conventional practitioners have superiority complex over traditional practitioners; they even ridicule and criticize them, and regard them as witchdoctors.

Moreover, the respondents were of the opinion that in traditional practice there is no documentation therefore information on the number of people circumcised and complications encountered is not available. Traditional practitioners perform their procedures in the bush and usually in secrecy and in unhygienic conditions. They use the same instrument for all clients and that traditional practitioners have limited skills on management of wounds and adverse events. 
Regarding the opportunities for collaboration majority of the respondents said, traditional practitioners are part of the community and they are accepted therefore it is possible to identify, mobilize and train them. The presence of Department of Traditional and Alternative Medicine, National AIDS Control Programme under one Ministry of Health and Social Welfare, Traditional practitioners' Association, provides a good opportunity for coordination. Most of the respondents were in favour of the involvement of traditional practitioners in scaling up safe male circumcision reducing HIV transmission. Furthermore, the accessibility to the health facilities in some areas is difficult therefore the involvement of traditional practitioners will be helpful. To implement the programme, the government should create a good environment for the two parties to collaborate and funds should be made available to support traditional male circumcision. On the other hand, some respondents were not in favour of the involvement of traditional practitioners in scaling up safe male circumcision. This was because only a proportion of the Tanzanian population practice traditional circumcision in Tanzania. Moreover, they said HIV is prevalent even in areas where male circumcision is common, therefore scaling up male circumcision alone will not reduce HIV infection transmission.

All respondents were of the opinion that scaling up circumcision for HIV prevention should be accompanied by the promotion of other intervention as the community might think that circumcision alone can prevent HIV transmission. Scaling up male circumcision using traditional practitioners might lead to an increase prevalence of adverse events. Older people might not be willing to be circumcised by a practitioner known to them (due to fear of stigma). They went further to recommend and encourage an integrated approach through health system strengthening including human resource capacity building at all levels.

As pre-requisite to the involvement of traditional practitioners in scaling-up safe traditional male circumcision, the key informants proposed that a situation analysis should be carried out to determine where and how traditional male circumcision is to be practised. The traditional practitioners should be recognised and involved in the planning for the proposed interventions. Communities' social, culture and beliefs should be explored. Training of practitioners should pay emphasis on hygiene, prevention of diseases transmission and safe use of equipment. Traditional practitioners should be provided with free surgical equipment and protective gears and be encouraged to use improved special premises. Like the district informants, respondents from the national level cautioned that male circumcision should not be compulsory.

Most of the respondents recommended the following to be considered: The association for traditional practitioners should be consulted and involved in the coordination and identification of the traditional practitioners to be incorporated in the programme. Traditional practitioners should be registered, regulated and supervised. A law to legalise their practice need to be enacted. There should be an improvement or provision of environment for traditional circumcision. Surgical equipment and materials for should be provided by the government. Specific time for conducting circumcision should be set so that health system is alerted in case there are any complications.

\section{Discussion}


In the study districts male circumcision both clinical and traditional is a common practice among their communities. Traditional male circumcision was most preferred in Monduli and Mkuranga than Bahi district. Cultural backgrounds were reported to be the main reasons for the preference of traditional circumcision. In Bahi and Monduli, circumcision is an integral part of a rite of passage to manhood, and is a test of bravely and endurance. Similar findings have been reported in both East and West Africa (Myers et al., 1985; Ajuwon et al., 1995; Doyle, 2005) and other part of the world (UNAIDS 2007). In some West African groups, circumcision is taken to represent a removal of "feminine" aspects of the male, turning boys into fully masculine males or it is symbolic of a boy entering into manhood (NECEP, 2006; Agberia, 2006). Similarly, in East Africa, among the Kalenjin and Maasai, circumcision is a rite of passage observed collectively by a number of boys every few years, and boys circumcised at the same time are taken to be members of a single age set. In this case, circumcision is associated with factors such as cohesion with boys of the same age for self-identify and spirituality. The rite of passage has been extensively described by van Gennep (1909). Similar to our findings, in the majority of cultures, circumcision is an integral part of a rite-of-passage to manhood, although originally it may have been a test of bravery and endurance (WHO/ UNAIDS, 2007).

Like in our study, culture and tradition play major roles for many ethnic groups elsewhere in Africa. Among ethnic groups of Bendel State in southern Nigeria, men's motivation for circumcision is to maintain their tradition. Similar to the findings in Monduli, in some settings among communities where circumcision is the norm, there is discrimination against non-circumcised men. Already studies have shown that among the Lunda and Luvale tribes in Zambia (Lukobo \& Bailey, 2007), the Bagisu in Uganda (Bailey et al., 1999) or the Yao in Malawi (Ngalande et al., 2006), it is unacceptable to remain uncircumcised; to the extent that forced circumcisions of older boys are common.

Male circumcision is also undertaken for religious, social and medical reasons. In Mkuranga male circumcision, practiced at an early age is associated with religion as most of the people are Moslems. Male circumcision is an embedded religious norm among many communities throughout the world (al-Sabbagh, 1996; Glass, 1999). For example, circumcision is commonly practiced in the Jewish and Islamic faiths. Jewish law states that circumcision is a 'mitzva aseh ("positive commandment" to perform an act) and is obligatory for Jewish-born males (Glass, 1999). Similarly, the Moslems consider circumcision is recommended as part of the Sunnah and hence, it is obligatory (al-Sabbagh, 1996). Islam is the largest religious group to practice male circumcision, and Islamic people practice circumcision as a confirmation of their relationship with God, and the practice is also known as 'tahera', meaning purification (Rizvi et al., 1999). It is most probably that the Kiswahili word "tohara" originated for the Arab word "tahera". Unlike in other parts of the world, only a few respondents in this study associated male circumcision with social reasons. In a number of countries, socio-economic factors also influence circumcision prevalence. Social concerns have been reported as the primary reason for circumcision in South Korea and Philippines (Oh et al., 2004; http://www.unaids.org/en/). When male circumcision was first practiced in the United Kingdom in the late $19^{\text {th }}$ and early $20^{\text {th }}$ century, it was most prevalent among the upper classes (Coulter \& McPherson, 1985).

Perceived health and sexual benefits were also mentioned as among the reasons for circumcision in the three districts. In more recent times, perceptions of improved hygiene and 
lower risk of infections through male circumcision have driven the spread of circumcision practices in a number of countries (Owusu-Danso, 2006; http://www.unaids.org/en/). In western Kenya, the majority of uncircumcised men and women irrespective of their preference for male circumcision perceive that it is easier for circumcised men to maintain cleanliness (http://artmatters.info/).

While male circumcision is being promoted as HIV prevention tool in high-risk heterosexual populations, there is concern about the procedure's effect on sexual function. In a study in western Kenya, adult male circumcision was not associated with sexual dysfunction. Circumcised men reported increased penile sensitivity and enhanced ease of reaching orgasm (Krieger et al., 2009). Perceived improvement of sexual attraction and performance has also been reported to motivate circumcision. In the Philippines, boys believe that women like to have sexual intercourse with circumcised men, while in South Korea circumcision is believed to increase sexual pleasure (Oh et al., 2004). In northwest Tanzania, younger men associated circumcision with enhanced sexual pleasure for both men and women (Nnko et al., 2001), and in South Africa, about half of men were reported to believe that women preferred circumcised partners (http://www.unaids.org/en).

In all the three districts there was no specific age for circumcision. However, most circumcisions were performed to include young adolescents of 7-25 years. Some other studies among the Maasai indicate that the male circumcision ceremony for boys takes place mostly between the age of 16-17 years and that in the old days; boys were not circumcised until they were considered mature (http://circlist.com/rites/maasai.html). It is becoming more common for circumcision to be delayed until the individual can give informed consent himself. Findings from elsewhere indicate that age at circumcision varies by country. Neonatal circumcision is common in Ghana (Owusu-Danso, 2006) and among the Jewish communities (Glass, 1999). In many other countries median age at circumcision varies from boyhood (median age 5-7 years in Burkina Faso (DHS, 2006), age 7-10 years in Zambia (Bowa, 2006), and age 8-16 years in Kenya (Agot \& Bailey, 2006) to the late teens or twenties in South Africa (Rain-Taljaard et al., 2003).

Findings from our study revealed that group circumcision ceremonies were most common among the communities in the three districts; but more particularly in Monduli and least common in Mkuranga. Group circumcision ceremonies are likely to lead to the use of one unsterilized surgical knife for more than one initiate. Like in our study, similar experiences have been reported elsewhere (Mayatula \& Mavundla, 1997; Naude, 2002).

The findings that there is a 7-year lapse between one period of circumcision and the next were quite common among many respondents in Monduli. This was described to be important because at times boys have to wait until they are in their mid 20's while their younger brothers catch up with them in the same age-group. While the Maasai perform male circumcision after every seven years, in Bahi and Mkuranga districts, traditional circumcision is most often performed every year during school holidays or the harvesting season. This has an implication in planning for the scaling up exercise to align with the already established circumcision seasons and frequencies.

In our study, the most frequently mentioned adverse events associated with traditional male circumcision included excessive bleeding, wound infection and amputation of the penis. Contrary to many other studies elsewhere, disfigurement of the penis and meatal stenosis were 
neither mentioned by the healthcare practitioners nor the communities. Meatal stenosis is a relatively common acquired condition (Angel, 2006; van Howe, 2006). In Africa, meatal stenosis among the most common serious complications or adverse events after circumcision in traditional settings (Meintjies, 1998; Mayatula \& Mavundla, 1997; Ahmed et al., 1999; Magoha, 1999; Meissner \& Buso, 2007; Peltzer et al., 2008). Like in our study, elsewhere circumcisions undertaken in non-clinical settings have been associated with significant risks of serious adverse events, including deaths due to septicaemia and gangrene (Peltzer et al., 2008).

Non use of anaesthesia in traditional male circumcision was noted. The belief behind is that tolerance of pain during circumcision is a measure of one being brave and fearless. On the other hand it makes a circumcised boy obedient and observant of what have been taught during the initiation process. Traditional practitioners do believe that anaesthetics use will impair erectile potency to circumcised men. However, the non-use of anaesthesia conflicts the objective of reducing pain in medical practice. The use of anaesthesia is likely to change the meaning of having brave and fearless individuals to an extent that some local communities may resist (Rennie et al. 2007).

In this study there was little variation in the cost between traditional and conventional circumcisions. There were proposal that for scaling up, traditional practitioners should be paid for the service. However, there was no agreement as to the mode of payment. Tanzania is following a mixed type of health system financing mechanism. Community Health Fund (CHF) and National Health Insurance Fund (NHIF) schemes are available. These schemes could also be used to cater for the circumcision services.

Traditional practitioners admitted to have no formal relationship with health workers, though sometimes they would consult them in the event of complicated cases. Most often the collaboration was described to be on friendly basis. Lack of good collaboration between health workers and traditional practitioner was said to be due to mistrust between the two groups. Similarly, historical suspicion and mistrust have divided traditional healers and health-care workers (Nyumbu, 2003; Mbwambo et al., 2007). Addressing the rift between these two groups is critical. Throughout much of the Sub-Saharan Africa, as many as $80 \%$ people consult traditional healers before seeking out clinical medical care; and a larger number of boys are circumcised by traditional practitioners (WHO/UNAIDS, 2007). However, like other indigenous knowledge and despite the fact that traditional practices are attaining increased popularity and demand, yet the efficacy, safety and quality of practice have not been thoroughly well established (Mbwambo et al., 2007).

Despite a number of challenges in the collaboration between traditional and conventional practitioners, most respondents agreed that there are opportunities for collaboration between the two groups. It was proposed that traditional practitioners should be involved in scaling up safe male circumcision as an effort to reduce HIV transmission; mainly because the health system is weak and cannot serve the whole community. Already, the recognition of traditional medicine practice worldwide has helped to reduce gaps that exist between traditional and conventional practitioners (Mbwambo et al., 2007). It is therefore important that policy and legal framework are formulated to govern the collaboration between the two practices in Tanzania. Strategies on how to strengthen linkage between traditional and conventional practitioners should include provision of health education to traditional 
practitioners on safe circumcision and HIV prevention; proper use anaesthetics; and postoperation care of wounds. To improve traditional male circumcision practices a number of issues need to be addressed. These include circumcision techniques and availability of surgical tool kit and medicine. There is however a need to identify and register all traditional practitioners.

Since male circumcision in Africa is typically practiced as a rite of passage from boyhood to manhood it provides an opportunity for its acceptability when it is to be scaled up as an HIVprevention strategy. Already a model that integrates HIV-prevention into pre-adolescent circumcision traditions has been successfully implemented on a small scale in eastern Kenya (Grant et al., 2004). However, as Rennie et al. (2007) pointed out large-scale preadolescent circumcision presents serious challenges. These include the facts that some aspects of traditional practices will need to be modified in order to align them with the goals of HIV prevention. Some traditional activities such as the use of unsterilized equipment and premises need to be discouraged. The fact that in some communities, sexual activity is encouraged soon after circumcision in order to complete the transition to manhood needs to be discouraged. This is likely to put an individual at a greatly increased risk of HIV acquisition.

In view of the findings of our study traditional circumcision is and will still have a role among many communities in Tanzania for a number of years to come. Under HIV situation, male circumcision should always be considered as part of a comprehensive HIV prevention package. Training and sensitization among traditional practitioners and the community is however important before scaling up. It is also equally important that a careful monitoring of the quality of follow-up care; national commitments to low-cost circumcisions to facilitate equitable access; flexible policies informed by concerns of local communities regarding if, when, where and how circumcisions should be performed; careful attention to the consent process and sustained condom promotion to minimize the risk of behavioural disinhibition; monitoring of circumcision promotion messages to ensure that prospective clients are aware of potential benefits and limits should be part and parcel of the scaling up programme.

\section{References}

Agberia, J.T. (2006) Aesthetics and rituals of the opha ceremony among the Urhobo people. Journal of Asian and African Studies 41, 249-260.

Agot, K. \& Bailey, R.C. (2006) Strategies and approaches for male circumcision programming. WHO meeting report: Strategies and Approaches for MC Programming, Geneva, 5-6 December 2006.

Ahmed, A.A., Mbibi, N.H., Dawam, D. \& Kalayi, G.D. (1999) Complications of traditional male circumcision. Annals of Tropical Paediatrics 19, 113-117.

Ajuwon, A.J., Brieger, W.R., Oladepo, O. \& Adeniyi, J.D. (1995) Indigenous surgical practices in rural south-western Nigeria: Implications for disease. Health Education Research 10, 379384.

al-Sabbagh, M.L. (1996) Islamic ruling on male and female circumcision. World Health Organization. p. 16. 
Angel, C.A. (2006) Meatal Stenosis. eMedicine. http://www.emedicine.com/PED/topic2356.htm. Retrieved on 09 June 2009.

Auvert, B., Taljaard, D., Lagarde, E., Sobngwi-Tambekou, J., Sitta, R. \& Puren, A. (2005) Randomized, controlled intervention trial of male circumcision for reduction of HIV infection risk : the ANRS 1265 trial. PLoS Medicine 2, 1-11.

Bailey, R.C. \& Egesah, O. (2006) Assessment of clinical and traditional male circumcision services in Bungoma District, Kenya: Complications Rates and Operational Needs. Special Report submitted to USAID, PSI, AIDSMark.

Bailey, R.C., Neema, S. \& Othieno, R. (1999) Sexual behaviours and other HIV risk factors in circumcised and uncircumcised men in Uganda. Journal of Acquired Immune Deficiency Syndrome 22, 294-301.

Bailey, R.C.; Moses, S., Parker, C.B., Agot, K., Maclean, I., Krieger, J.N., Williams, C.F.M., Campbell, R.T. \& Ndinya-Achola, J.O. (2007) Male circumcision for HIV prevention in young men in Kisumu, Kenya: a randomised controlled trial. The Lancet 369 (9562), 643656.

Bowa, K. (2006) Strategies and approaches for male circumcision programming. WHO meeting report: Strategies and Approaches for MC Programming, Geneva, 5-6 December 2006.

Coulter, A. \& McPherson, K. (1985) Socio-economic variations in the use of common surgical operations. British Medical Journal 291 (6489), 183-187.

DHS (2006) Demographic and Health Surveys. MEASURE DHS, 2006 (http:www.measuredhs.com). Accessed 7 June 2009.

Dogde, O.G. \& Kaviti, J.N. (1965) Male circumcision among the people of East Africa and the incidence of genital cancer. East African Medical Journal 42, 98-105.

Donoval, B.A., Landay, A.L., Moses, S., Agot, K., Ndinya-Achola, J.O., Nyagaya, E.A., MacLean, I. \& Bailey, R.C. (2006) HIV-1 target cells in foreskins of African men with varying histories of sexually transmitted infections. American Journal of Clinical Pathology, 125, 386-391.

Doyle, D. (2005) Ritual male circumcision: a brief history. Journal of the Royal College of Physicians Edinburgh 35, 279-285.

Glass, J.M. (1999) Religious circumcision: a Jewish view. BJU International 83 (Suppl. 1), 17-21.

Grant, E., Brown, J., Michen, K., Grant, A., Manuthu, E. \& Njeru, J. (2004) Seizing the day: right time, right place and right message for adolescent reproductive sexual health. Lessons from the Meru of Eastern province Kenya. International Journal of Men's Health3, 189-196.

Gray, R.H., Kigozi, G., Serwadda, D., Makumbi, F., Watya, S., Nalugoda, F., Kiwanuka, N., Moulton, L.H., Chaudhary, M.A., Chen, M.Z., Sewankambo, N.K., Wabwire-Mangen, F., Bacon, M.C., Williams. C.F., Opendi, P., Reynolds, S.J., Laeyendecker, O., Quinn, T.C. \& Wawer, M.J. (2007) Male circumcision for HIV prevention in young men in Rakai, Uganda: a randomised trial. Lancet 369 (9562), 657-666.

Halperin, D. \& Bailey, R.C. (1999) Male circumcision and HIV infection: Ten years of counting. Lancet 354, 1813-1815.

Hankin, C. (2006) Overview of the current evidence on male circumcision and HIV prevention. UNAIDS. http://www.global-campaign.org/ 
Krieger, J.N., Mehta, S.D., Bailey, R.C., Agot, K., Ndinya-Achola, J.O., Parker, C. \& Moses, S. (2009) Adult Male Circumcision: Effects on Sexual Function and Sexual Satisfaction in Kisumu, Kenya. The Journal of Sexual Medicine 5, 2610-2622.

Lukobo, M. \& Bailey, R.C. (2007) Acceptability of male circumcision for prevention of HIV infection in Zambia. AIDS Care 19, 471-477.

Magoha, G.A. (1999) Circumcision in various Nigerian and Kenyan hospitals. East African Medical Journal, 76, 583-586.

Mayatula, V. \& Mavundla, T.R. (1997) A review on male circumcision procedures among South African blacks. Curationis 20, 16-20.

Mbwambo, Z.H., Mahunnah, R.L.A. and Kayombo, E.J. (2007) Traditional health practitioner and the scientist: bridging the gap in contemporary health research in Tanzania. Tanzania Health Research Bulletin 9, 115-120.

Meintjies, G. (1998) Manhood at a Price: Socio-Medical Perspectives of Xhosa Traditional Circumcision. Volume 1. Institute of Social and Economic Research. Rhodes University, South Africa.

Meissner, O. \& Buso, D.L. (2007) Traditional male circumcision in the Eastern Cape - scourge or blessing? South African Medical Journal 97, 371-373.

Mills, E., Cooper, C., Anema, A. \& Guyatt, G. (2008) Male circumcision for prevention of heterosexually acquired HIV infection: a meta-analysis of randomized trials involving 11,050 men. HIV Medicine 9, 332-335.

Moses, S., Bradley, J.E., Nagelkerke, N.J.D., Ronald, A.R., Ndinya-Achola, J.O. \& Plummer, F.A. (1990) Geographical patterns of male circumcision practices in Africa: Association with HIV seroprevalence. International Journal of Epidemiology 19, 693-697.

Myers, R.A., Omorodion, F.I., Isenalumhe, A.E. \& Akenzua, G.E. (1985) Circumcision: its nature and practice among some ethnic groups in southern Nigeria. Social Science and Medicine 21, 581-588.

Naude, J.H. (2002) Reconstructive urology in the tropical and developing world: a personal perspective. BJU International 89 (Suppl. 1), 31-36.

NECEP (2006) Circumcision amongst the Dogon. The Non-European Components of European Patrimony Database. 2006. http://www.necep.net/articles.php?. Retrieved on 29 May 2009.

Ngalande, R.C., Levy, J., Kapondo, C.P. \& Bailey, R.C. (2006) Acceptability of male circumcision for prevention of HIV infection in Malawi. AIDS and Behavior 10, 377-385..

Nnko, S., Washija, R., Urassa, M., \& Boerma, J.T. (2001) Dynamics of male circumcision practices in northwest Tanzania. Sexually Transmitted Diseases 28, 214-218.

Nyumbu, M. (2003) Traditional healers and health workers partner in Zambian care. Global AIDSLink 82, 10.

Oh, S.J. Kim, K.D.,, Kim, K.M., Kim, K.S., Kim, K.K., Kim, J.S., Kim, H.G., Woo, Y.N., Yoon, Y.L., Lee, S.D., Han, S.W., Lee, S.I. \& Choi, H (2004) Knowledge of and attitude towards circumcision of adult Korean males by age. Acta Paediatrica 93, 1530-1534.

Owusu-Danso, O. (2006) Strategies and approaches for male circumcision programming. WHO meeting report: Strategies and Approaches for MC Programming, Geneva, 5-6 December 2006. 
Patterson, B.K., Landay, A., Siegel, J.N., Flener, Z., Pessis, D., Chaviano, A. \& Bailey, R.C. (2002) Susceptibility to Human Immunodeficiency Virus-1 infection of human foreskin and cervical tissue grown in explants culture. American Journal of Pathology American Journal of Pathology 161, 867-873.

Peltzer, K., Nqeketo, A., Petros, G. \& Kanta, X. (2008) Traditional circumcision during manhood initiation rituals in the Eastern Cape, South Africa: a pre-post intervention evaluation. BMC Public Health 8, 64.

Rain-Taljaard, R.C., Lagarde, E., Taljaard, D.J., Campbell, C., Macphail, C., Williams, B. \& Auvert, B. (2003) Potential for an intervention based on male circumcision in a South African town with high levels of HIV infection. AIDS Care 15, 315-327.

Rennie, S., Muula, A.S. \& Westreich, D. (2007) Male circumcision and HIV prevention: ethical, medical and public health tradeoffs in low-income countries. Journal of Medical Ethics 33, 357-361.

Rizvi, S.A.H., Naqvi, S.A.A., Hussain, M. \& Hasan, A.S. (1999) Religious circumcision: a Muslim view. BJU International 83 (S1), 13-16.

Urassa, M., Todd, J., Boerma, J.T., Hayes, R. \& Isingo, R. (1997) Male circumcision and susceptibility to HIV infection among 12,551 men in Tanzania. AIDS 11, 73-80.

van Gennep, A. (1909) The Rites of Passage. Chicago, University of Chicago Press.

van Howe, R.S. (2006) Incidence of meatal stenosis following neonatal circumcision in a primary care setting. Clinical Pediatrics 45, 49-54.

Westercamp, N. \& Bailey, R.C. (2007) Acceptability of male circumcision for prevention of HIV/AIDS in Sub-Saharan Africa: A review. AIDS and Behavior 11, 341-355.

WHO/UNAIDS (2007) Male circumcision: global trends and determinants of prevalence, safety and acceptability. World Health Organization and Joint United Nations Programme on HIV/AIDS. UNAIDS/07.29E/JC 1320E.

Williams, B.G., Lloyd-Smith, J.O., Gouws, E., Hankins, C., Getz, W.M., Hargrove, J., de Zoysa, I., Dye, C. \& Auvert, B. (2006) The potential impact of male circumcision on HIV in subSaharan Africa. PLoS Medicine 3:e262. 